\title{
About the relationship between auroral electrojets and ring currents
}

\author{
A. Grafe ${ }^{1}$, Y. I. Feldstein ${ }^{2}$ \\ ${ }^{1}$ GeoForschungsZentrum Potsdam, Telegrafenberg D-14473 Potsdam, Germany \\ ${ }^{2}$ Institute of Terrestrial Magnetism, Ionosphere and Radio Wave Propagation Troitsk, Moscow Region, Russia
}

Received: 22 January 1999 / Revised: 3 March 2000 / Accepted: 7 April 2000

\begin{abstract}
The relationship between the storm-time ring current and the auroral electrojets is investigated using IMAGE magnetometer data, $D_{S t}$ and H-SYM, and solar wind data. Statistical results as well as the investigation of single events show that the auroral electrojets occur also during nonstorm conditions without storm-time ring current development and even during the storm recovery phase of increasing $D_{S t}$. A close correlation between electrojet intensity and ring current intensity was not found. Though the eastward electrojet moves equatorward during the storm main phase there is no unequivocal relationship between the movement of the westward electrojet and the ring current development. All these results suggest that the auroral electrojets and the ring current develop more or less independently of each other.
\end{abstract}

Key words: Magnetospheric physics (magnetosphereionosphere interactions; storms and substorms)

\section{Introduction}

For a long time the question of how close the relationship is between geomagnetic field variations in the auroral zone, in low latitudes and near the equator has been a puzzle. Since the 1960s it has been known and accepted that these geomagnetic field variations, which are the most characteristic features of geomagnetic storms, are caused by three-dimensional ionosphericmagnetospheric current systems. One of the most important basic problems of magnetosphere physics and especially of the disturbed magnetosphere is the interrelation between the substorm current system and

Correspondence to: A. Grafe e-mail: armgrafe@t-online.de the current systems which contribute to the storm-time variation $D_{S t}$, the ring current $(D R)$, the tail current $(D T)$ and the Chapman-Ferraro current $(D C F)$ current system. In particular the interrelation between substorm and ring current current system has been at the forefront of discussions. Three possibilities appear to be conceivable:

1. The ring current is the cause of the auroral electrojets

2. The auroral electrojets are the cause of the ring current

3. There is no relationship between ring current and auroral electrojet development though they are caused by one and the same source

Because of these possibilities the question about the temporal occurrence of $D R$ and $D P$ was very important in the 1960s. However, the discussions and suggestions are quite controversial. Research by Akasofu and Chapman (1963) found that $D R$ and $D P$ develop quite simultaneously, while Feldstein and Starkov (1968) and Shevnin et al. (1968) showed that the position of the auroral oval is controlled by the intensity of the ring current. For example a $D_{S t}$ value of $-100 \mathrm{nT}$ corresponds to the equatorward boundary of auroral oval at midnight at a geomagnetic latitude of $59^{\circ}$. On the other hand Akasofu and Yoshida (1966) found that the increase of the $D R$ current often occurs earlier than the substorm begins. In particular it occurred prior to the recurrent geomagnetic storms which are characterized by the absence of a storm sudden commencement event. By way of contrast Pudovkin et al. (1968), Davis and Parthasarathy (1967) and Haurwitz (1969) showed that $D P$ often increases before the $D R$ increase. Later Eather and Carovillano (1971) found that the ring current is source for proton auroras and Kamide and Fukushima (1972) considered that the asymmetric ring current is the source of the eastward electrojet. Only after the appearance of in-situ satellite data was it discovered that obviously the ring current during magnetic storms is generated mainly by ionospheric energetic particles, especially by ionospheric $0^{+}$(Balsi- 
ger et al., 1980, 1983; Sharp et al., 1983; Whalen, 1983). One of the first suggestions that energetic ions of ionospheric origin appear in the magnetospheric tail came from Banks and Holzer (1968). On the basis of these observations it is not surprising that many believe that the ring current formation is mostly caused by the substorm events (e.g. Liu and Rostoker, 1995; Rostoker 1997). However, this idea was rejected by Iyemori and Rao (1996). They considered that the frequent occurrence of substorms is not the cause of the ring current development. This idea is supported by the investigations of Siscoe and Petschek (1997). Iyemori and Rao's (1996) work indicated that there is no direct interrelation between substorm and ring current intensification. They are two independent processes which are possibly caused by the same source. Rostoker et al. (1997a, b) criticized that the paper of Iyemori and Rao (1996) did not clearly show in the observations an independent ring current development during the substorm expansion phase. We establish that the discussion of these important magnetospheric processes is at present of great interest. Due to better ground-based and satellite observations this discussion can be carried out today with much better data than in the past.

Our aim is to present our opinion on these interesting relationships. In the first part we investigate whether or not a relationship exists between the occurrence of the intensification of the auroral electrojets and the ring current (or $D_{S t}$ ) during the different storm phases and nonstorm conditions. In the second part we shall describe the process of the equatorward movement of the auroral electrojets and possible relationships to the development of the ring current (or $D_{S t}$ ). Solar wind conditions and the behavior of the interplanetary magnetic field will be taken into account also in these investigations.

\section{Data}

For statistical and event investigations following data were used: mean hourly $D_{S t}$ values from September 1991 to December 1996, hourly and 1 minute AL values for 1990, the IMAGE magnetometer chain data from 1992 to 1996,1 minute SYM-H data from WDC-C2, Kyoto, for special events, and the corresponding solar wind and interplanetary magnetic field data of the WIND satellite (Table 1). We used data of the solar wind velocity $\mathbf{V}$, solar wind density $N$ and the southward component $B_{Z}$ of the interplanetary magnetic field.

We disregarded the data from the poleward IMAGE stations, known as the Svalbard stations because the position of the centre of the eastward and the westward electrojet was mostly southward of Soraya. The IMAGE data were used to estimate the position of the centre of both electrojets. This is the latitude for $\Delta Z=0$. To work out the time development of the electrojet movement it was necessary to draw latitudinal profiles for many time instants. Another parameter of the electrojet is the poleward and the equatorward bound-
Table 1. The IMAGE stations which were used

\begin{tabular}{llll}
\hline Code & Name & CGM-latitude & CGM-longitude \\
\hline NUR & Nurmijärvi & 56.84 & 102.48 \\
HAN & Hankasalmi & 58.66 & 104.94 \\
OUJ & Oulujärvi & 60.92 & 106.51 \\
PEL & Pello & 63.49 & 105.37 \\
SOD & Sodankylä & 63.85 & 107.71 \\
MUO & Muonio & 64.65 & 105.70 \\
KIL & Kilpisjärvi & 65.81 & 104.32 \\
MAS & Masi & 66.10 & 106.94 \\
KEV & Kevo & 66.23 & 109.75 \\
SOR & Soroya & 67.27 & 106.74 \\
\hline
\end{tabular}

ary. Clearly would be useful to determine the movement of these boundaries during the substorm process. To do this requires estimation of the electrojet width, a laborious and unreliable process at present.

To separate the influence of the Chapman-Ferrarocurrent $(D C F)$ on $D_{S t}$ we have used the formula $D C F=b V \sqrt{ } N$. For $b$ we have taken $b=0.30 \mathrm{nT}(\mathrm{eV}$ $\left.\mathrm{cm}^{-3}\right)^{1 / 2}$ following Burton et al. (1975). Then it was calculated that $D R=D_{S t}-D C F$. However, we must always consider that the $D R$ calculation by virtue of this formula is not only the ring current magnetic field but also contains the tail current magnetic field $D T$. There is evidence that $D T$ is not infinitely small but of the same order as the ring current magnetic field at the main phase of the magnetic storm (Alexeev et al., 1996). However, the estimation of $D T$ as part of $D_{S t}$ was accomplished using a special model of the tail current (Alexeev et al., 1996). There is no evidence that this model is correct. Therefore, in the following investigation we neglect $D T$.

\section{Occurrence of ring current and auroral electrojets during storm and nonstorm conditions}

\section{Statistical results}

It is generally interesting to know about the occurrence of the auroral electrojets during different storm phases and nonstorm intervals. To investigate this issue we took all pronounced positive $(>200 \mathrm{nT})$ and negative $(<-300 \mathrm{nT}$, in addition to two events) bay disturbances which occurred in the auroral zone along the IMAGE magnetometer chain from September 1991 to December 1996. This is an arbitrary choice of thresholds, however, smaller absolute threshold values would cause the amount of data much. It would be necessary for such an investigation to separate convection and explosive events. Sun et al. (1998) have done this recently using the method of natural orthogonal components. They were able to show that it is possible to separate single substorm events in directly driven $(D P 2)$ and unloading components $(D P 1)$. Using this method they need time series of the ionospheric equivalent current function and therefore, magnetic field data of an auroral latitude circle. We also found work by Weimer (1999) showing 


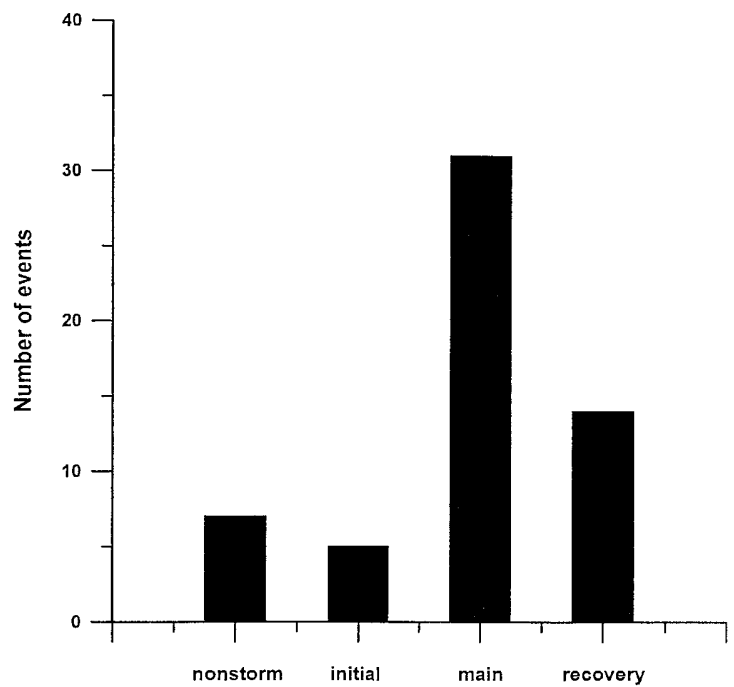

Fig. 1. Histogram of the occurrence of the eastward electrojet during different storm phases. September 01, 1991-December 31, 1996

different electric potential patterns of this two components. In our case we have only one meridian chain data. For these there is no easy method to make such a separation at present. In the time interval (1991-1996) we have found altogether 57 events of the eastward electrojet and 539 of the westward electrojet. All these events were compared with $D_{S t}$ at their occurrence time in order to find the phase of activity. Thereby a disturbance was designated as a storm when a clear main and recovery phase were discernible. $D_{S t}$ in the maximum of the main phase must be $<-20 \mathrm{nT}$. All other disturbances which did not fulfill this condition were taken as events occurring during nonstorm condi-

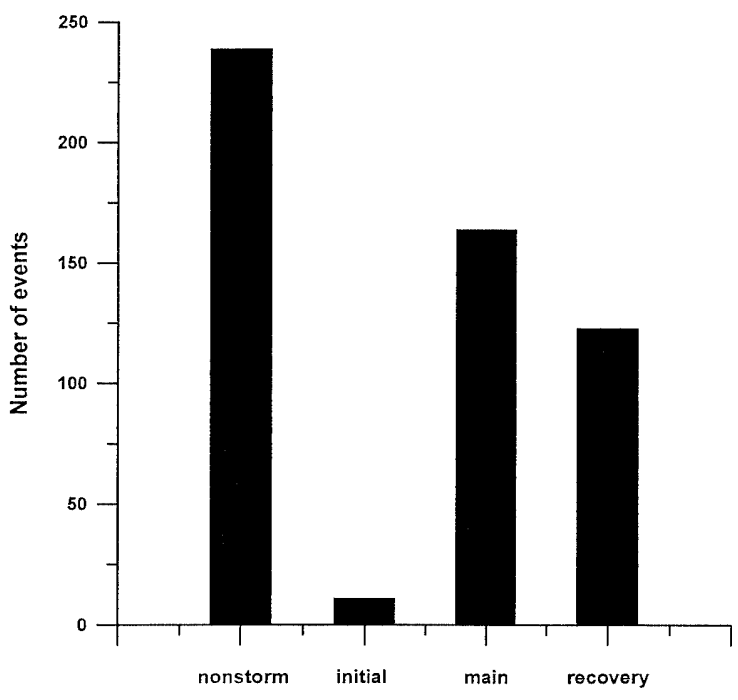

Fig. 2. Histogram of the occurrence of the westward electrojet during different storm phases. September 01, 1991-December 31, 1996

tions. Sometimes decision between late recovery phase and nonstorm conditions was not easy. The distribution of these events at the different phases of activity for the eastward electrojet are presented in Fig. 1 and for the westward electrojet in Fig. 2. First of all it should be emphasized that the auroral electrojets appear independently of the storm phases and even during nonstorm quasi-quiet conditions. Then the two figures show a different characteristic behaviour of the occurrence of these two electrojets. The eastward electrojet occurs most frequently during the storm main phase but the westward one during nonstorm conditions. The westward electrojet occurs rather often during the storm
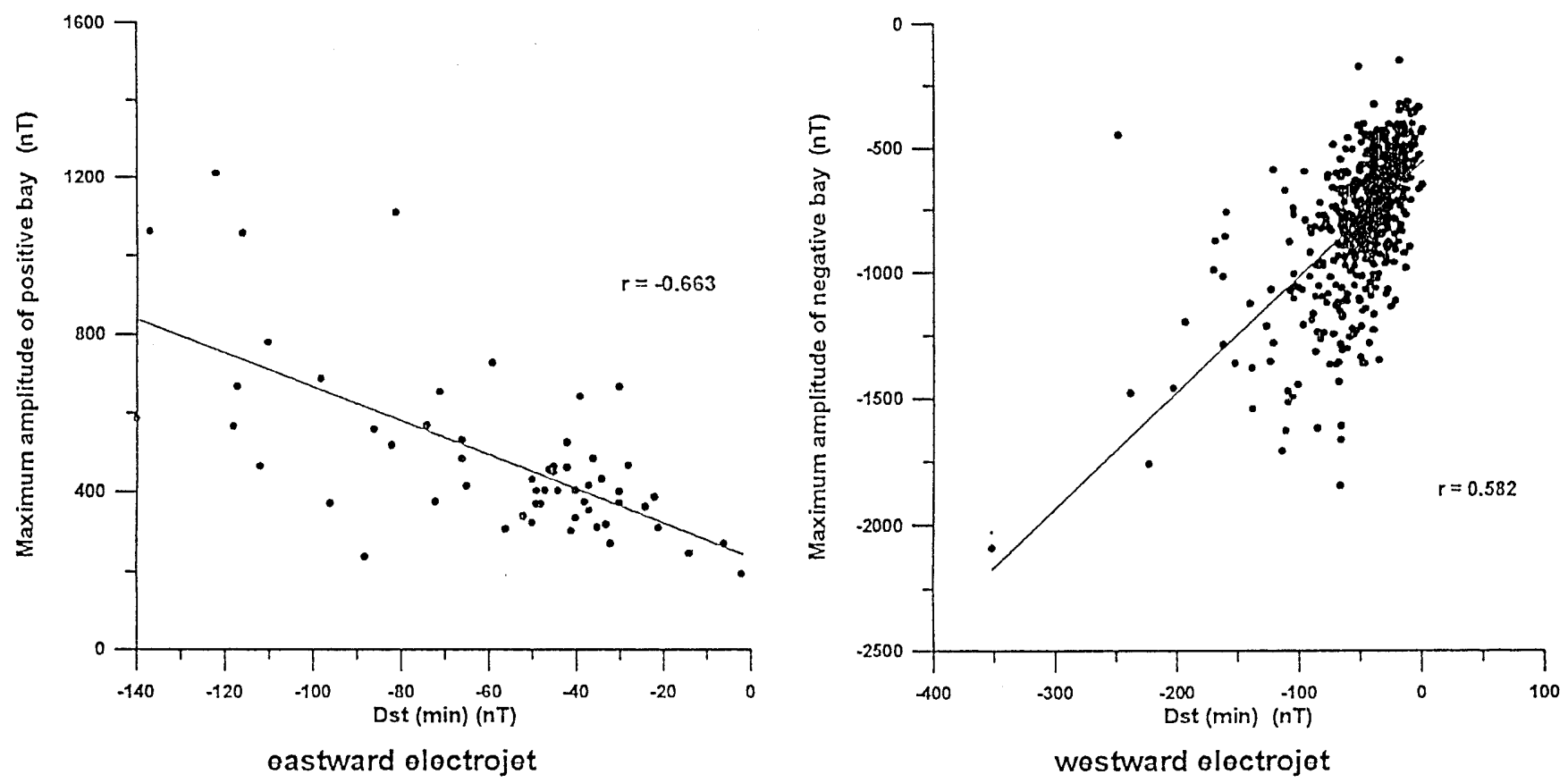

Fig. 3. Relationship between maximum auroral electrojet magnetic field intensity and $D_{s t}$ minimum during the time of the bay, (for all bay events from September 1991 to December 1996) 

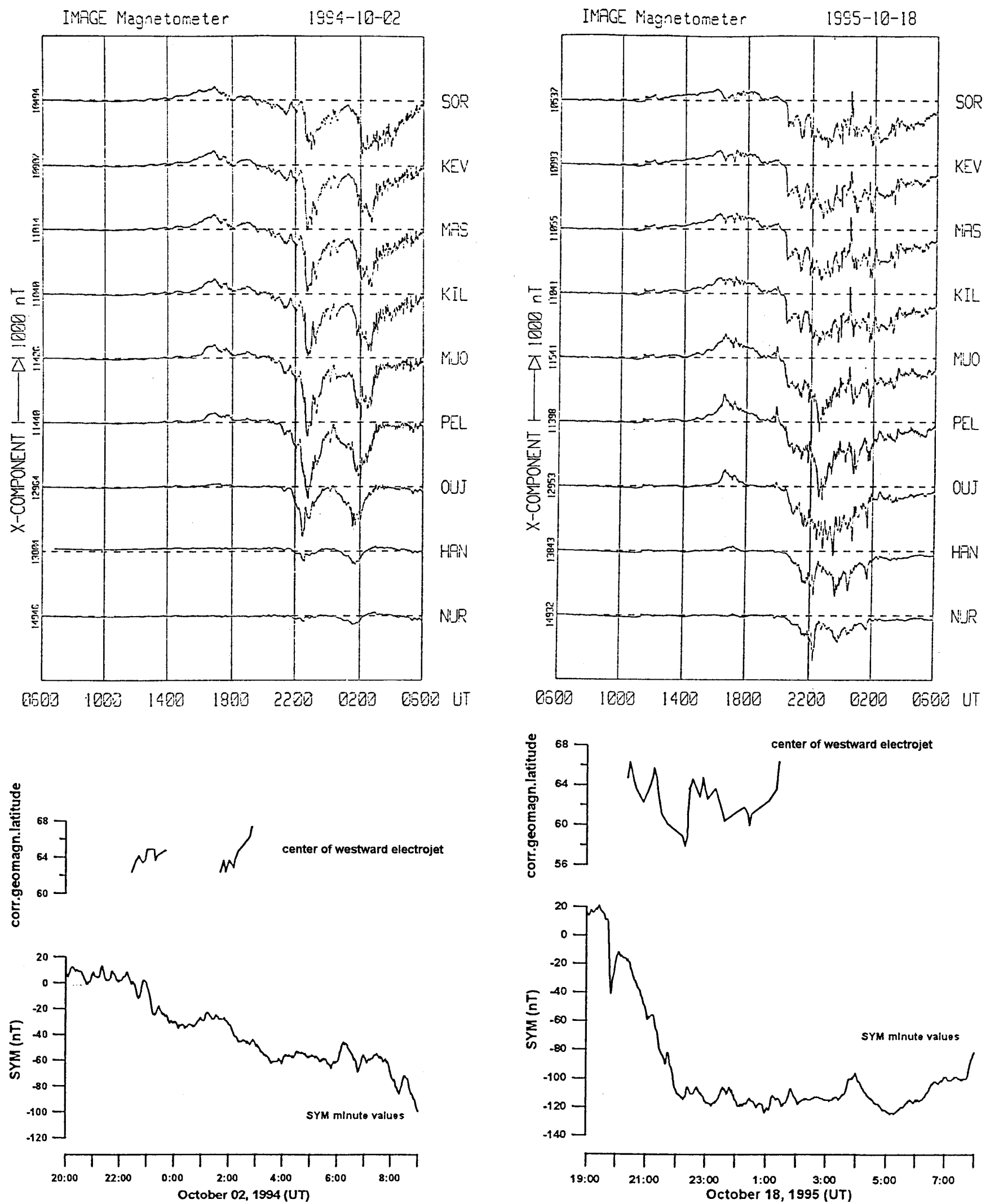

Fig. 4. Two examples of the movement of westward electrojet centre during the storm main phase

recovery phase in comparison with the storm main phase. The eastward electrojet appears not so often during the storm recovery phase.
Another important question concerning the relationship between $D_{S t}$ and the auroral electrojets is as follows: how close is the correlation between $D_{S t}$ and 
A. Grafe, Y. I. Feldstein: About the relationship between auroral electrojets and ring currents
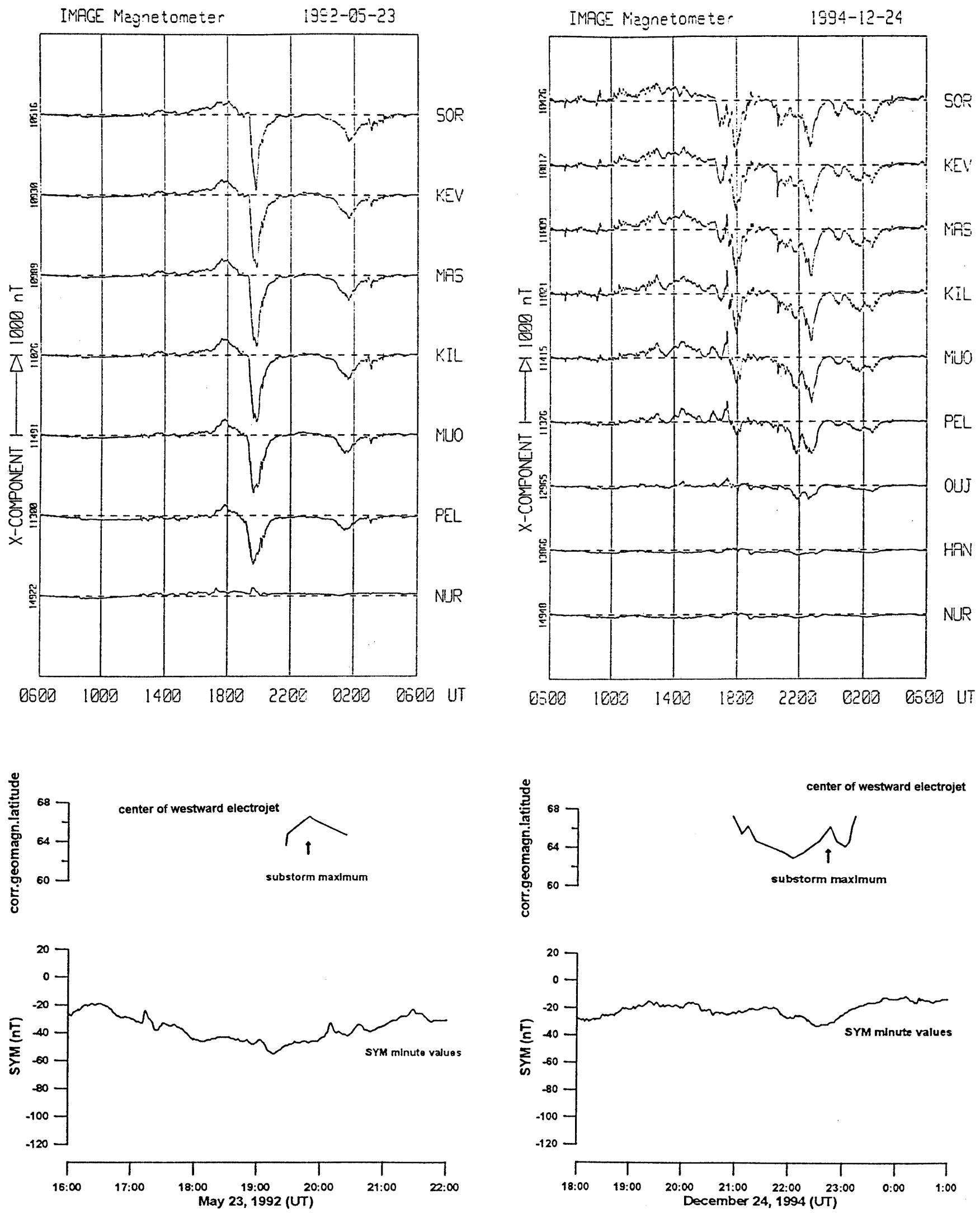

Fig. 5. Two examples of the movement of westward electrojet centre during the storm recovery phase

electrojet intensity? The result is shown in Fig. 3. Here we used the maximum auroral electrojet magnetic field intensity along the magnetometer chain. It is clearly seen that for both electrojets the correlation between the $D_{S t}$ and electrojet, intensity is not very high. Though there is recognizable tendency that the more intensive the $D_{S t}$ 

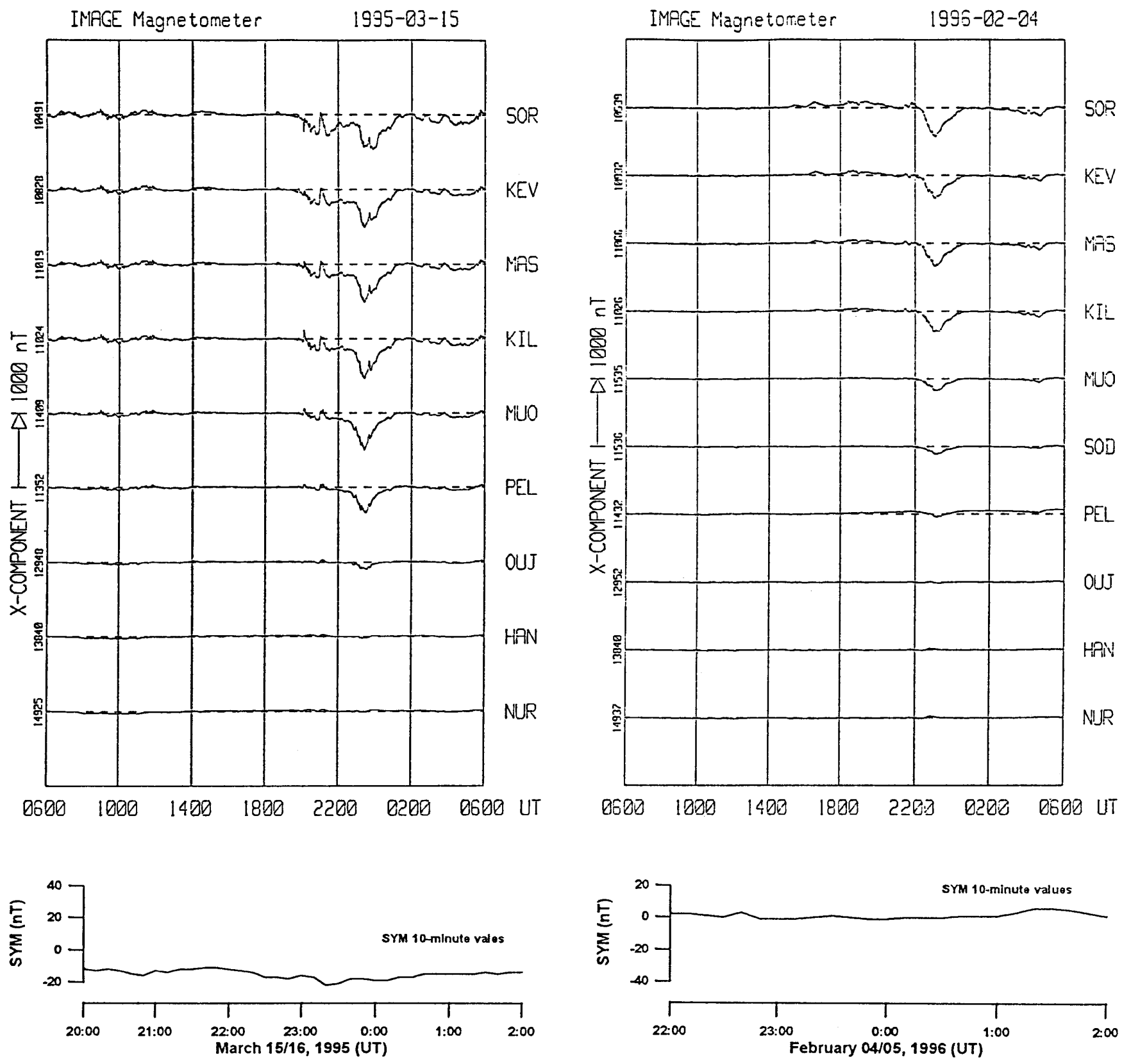

Fig. 6. Two examples of occurrence of substorm during nonstorm conditions

the more intensive the electrojets, the scattering of the scatter diagrams of Fig. 3 is great. The correlation is higher for the eastward electrojet than for the westward one. This shows that the eastward electrojet follows more closely the development of $D_{S t}$ than the westward one. Figure 3 also shows that the intensity in $D_{S t}$ is higher for the westward electrojet than for the eastward one. We do not have any explanation for this.

\section{Special events}

Westward electrojet

We have seen that obviously substorms occur at all storm phases and also during nonstorm conditions.
Figures 4-6 illustrate this fact by some single substorm events. In the upper panel of these figures the IMAGE magnetometer magnetograms are shown. Before September 1992 the IMAGE had only 7, later 9 and today 10 stations. The lower panels show the SYM-H values of Iyemori (1990), which are available at the WDC-C2 in Kyoto. Figure 4 shows two examples of substorms occurring during the storm main phase. SYM-H decreases considerably during the time of substorm development in the auroral zone. However, strong substorms can develop also during the storm recovery phase, as Fig. 5 illustrates. The variations of SYM-H are very small at the substorm times. We emphasize that this is a very important observation. Obviously strong substorms occurring during the storm recovery phase do not influence the ring current decay. This is in accor- 

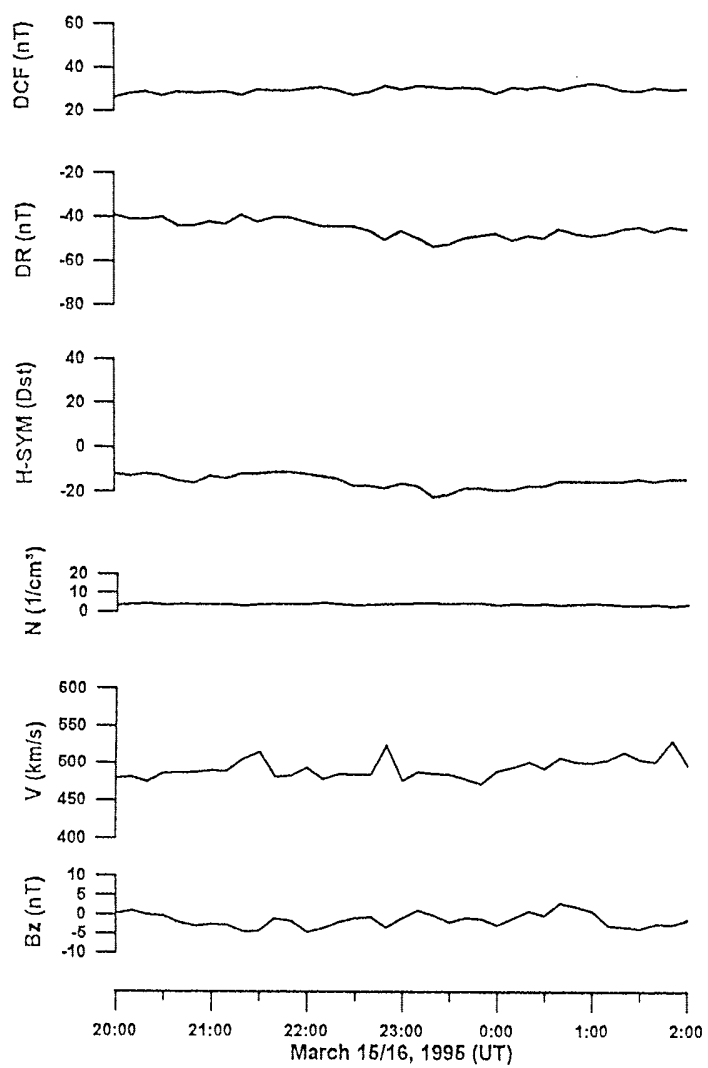

Fig. 7. $D R$ and $D C F$ values during the two substorms shown in Fig. 6 calculated from the solar wind data

dance with Kamide et al. (1998). As Fig. 6 shows substorms can appear also during nonstorm conditions. On the right panel of Fig. 6 SYM-H is even positive.

Of course, it is an important question whether $D_{S t}$ or SYM-H is the right parameter to clarify the relationship between substorm and ring current. Sometimes $D C F$ has the same magnitude as $D R$ so that $D_{S t}$ shows no effect. However it is possible to find out this for the nonstorm events of Fig. 6 because solar wind and interplanetary magnetic field data of the satellite WIND are available. Figure 7 shows the WIND data and the calculated variations of $D R$ and $D C F$ for these two events. As $D R$ variation testifies there is no effect of the substorm on the ring current in the both events. But it is necessary always to take into account that the tail current influence is contained in this $D R$ estimation. For the two events $D C F$ is about $30 \mathrm{nT}$ and $D R$ about -30 to $-40 \mathrm{nT}$. $B_{Z}$ is about zero.

Eastward electrojet

The statistics show that the eastward electrojet occurs mainly during the storm main phase when the ring current intensity is increasing. Some examples are shown in Figs. 8 and 9. On September 9, 1992 (Fig. 8), the eastward electrojet increases about 1000 UT (about 1230 MLT) at the same time when SYM decreases and the maximum of the positive bay is reached about 1300 UT at the end of the main phase. A similar behaviour can be established during the storm on May 16, 1995.
The maximum of positive bay is reached one hour later, about 1400 UT.

However, there are also events occurring during the storm recovery phase and nonstorm conditions. The positive bay disturbance on November 27, 1994, is an example of an occurrence during the recovery phase. In the lower panel of Fig. $9 D R$ and $D C F$ are represented. There is no change of $D C F$ during the positive bay. Its maximum has been reached about 1200 UT at the time of increasing $D R$. When the positive bay is seen on February 14, 19951200 to 1800 UT there are nonstorm conditions. Again $D R$ does not show remarkable changes at this time. Thus, we can state that the eastward electrojet also appears at all times apart from extremely quiet conditions.

\section{Movement of the auroral electrojets and development of $\mathrm{D}_{\mathrm{ST}}$}

\section{Statistical results}

To understand the relationship between electrojet and ring current development it is of great importance to consider the movements of the electrojets during these events. As already mentioned we can take into account only the movement of the electrojet centre. Of course, we would get a better picture of electrojet movement if we had addition knowledge of the motion of the poleward and equatorward edge of both electrojets. This 

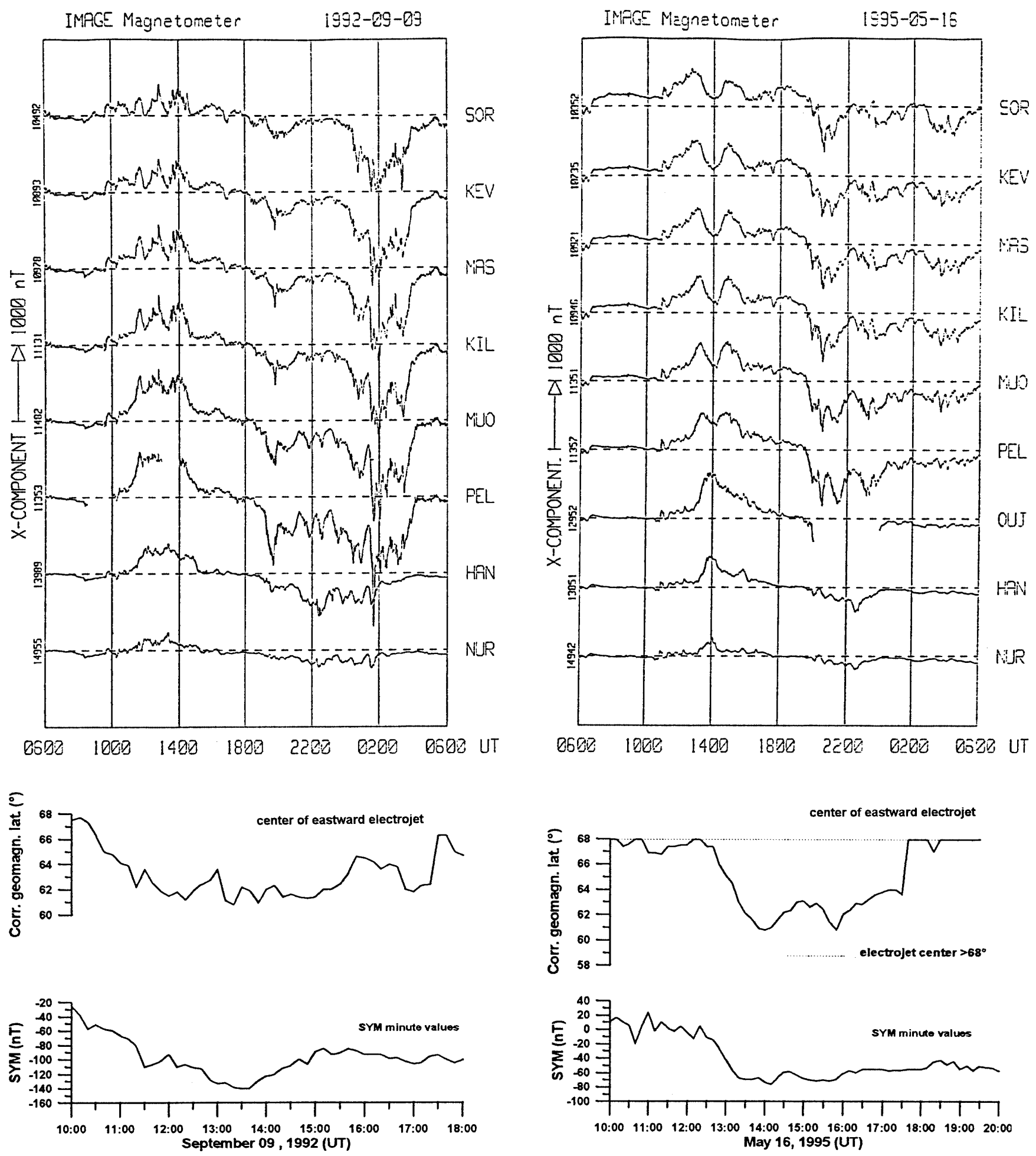

Fig. 8. Two examples of occurrence of the eastward electrojet magnetic field during the storm main phase

would require estimation the width of the electrojets, which is a very difficult task because the distribution of the electrojet current density is unknown as a rule. For instance, the question is whether or not there is any dependence of the electrojet movement direction on the ring current intensification or decay. The result of the statistical investigation using the observations from September 1991 to December 1996 is shown in Fig. 10 for the eastward electrojet and in Fig. 11 for the westward electrojet. Here the same data set as for Figs. 1 and 2 was used. In these figures all events are divided again in to four groups, i.e. events occurring during initial, main and recovery phases and during nonstorm conditions. In Figs. 10 and $11 \mathrm{~N}$ marks northward movement of the electrojet, S marks southward movement and $\mathrm{K}$ indicates that the position of the 

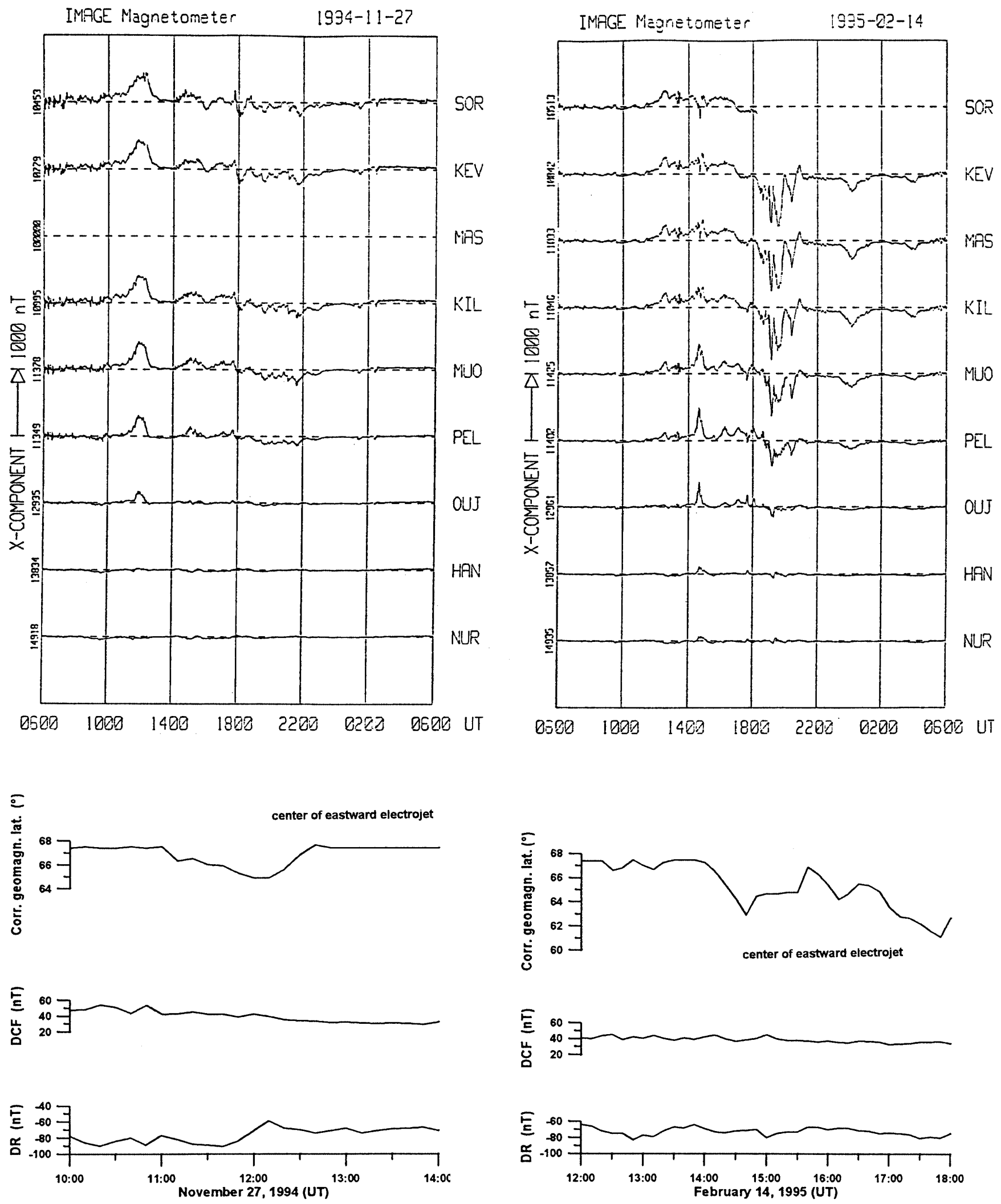

Fig. 9. Two examples of the eastward electrojet magnetic field during late recovery phase and nonstorm conditions

electrojet was not changed. Figure 10 shows, as a rule, that the eastward electrojet moves predominantly equatorwards at all disturbance phases. However, sometimes the position is not changed, and a poleward motion occurs very rarely. The conditions are quite different for the westward electrojet. The westward electrojet moves at first polewards at the beginning of the substorm expansion phase at about $50 \%$ of all events. However, 


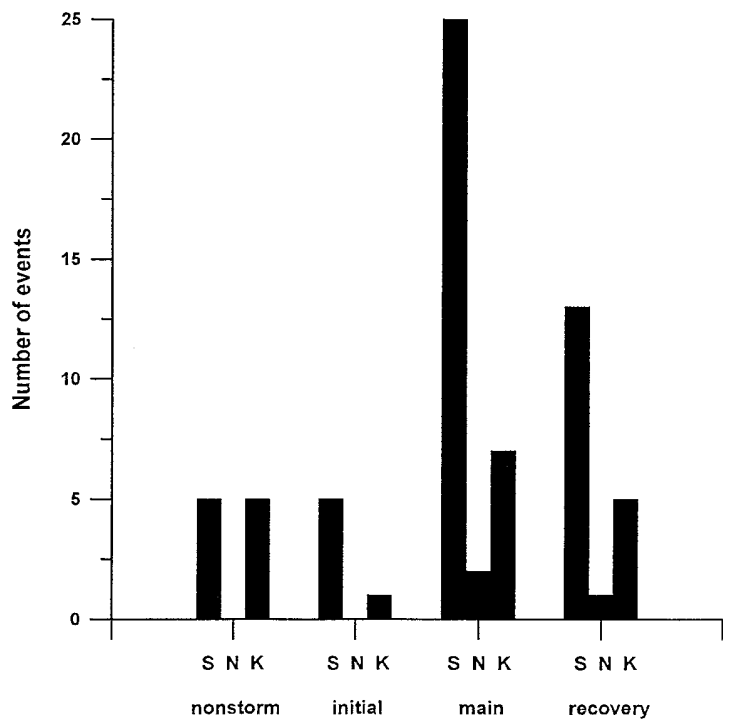

Fig. 10. Histogram of the direction of the movement of eastward electrojet during different storm phases. $\mathrm{S}$ is movement to south, $\mathrm{N}$ to north and $\mathrm{K}$, the electrojet position is nearly constant. September 01, 1991 to December 31, 1996

it is very rare that the westward electrojet moves at first equatorwards or does not change its position. What is the reason that the westward electrojet reacts so differently? This is a very interesting and important question, which an investigation of some special events may illuminate.

\section{Special events}

\section{Westward electrojet}

In the lower panel of Figs. 4 and 5 besides the variation of SYM-H the respective position of the westward electrojet centre is also presented. For the main phase (Fig. 4) together with the recovery phase (Fig. 5) two different events are shown. For the first event shown in the left panel the westward electrojet moves at first polewards and for the other event (in the right panel) it moves equatorwards. Although for the event on October 18, 1995 the electrojet moves further equatorwards, to a latitude of about $58^{\circ}$, it is remarkable that the electrojet movement during the recovery phase can reach similar low latitudes as during the main phase. One can observe the same behaviour even during nonstorm conditions as Fig. 12 shows. In Fig. 12 two substorms occurring during nonstorm conditions are presented. SYM-H is very low. The left panel illustrates again a poleward-moving electrojet at the substorm beginning and the right panel shows an equatorwardmoving electrojet. Of course it is remarkable that during nonstorm conditions the electrojet can also reach such low latitudes as on April 12, 1994, during the early main phase. On the left panel of Fig. 13 the relationship between the most equatorward position of the westward electrojet centre and the maximum value of SYM during the time of the substorm is shown. The correlation

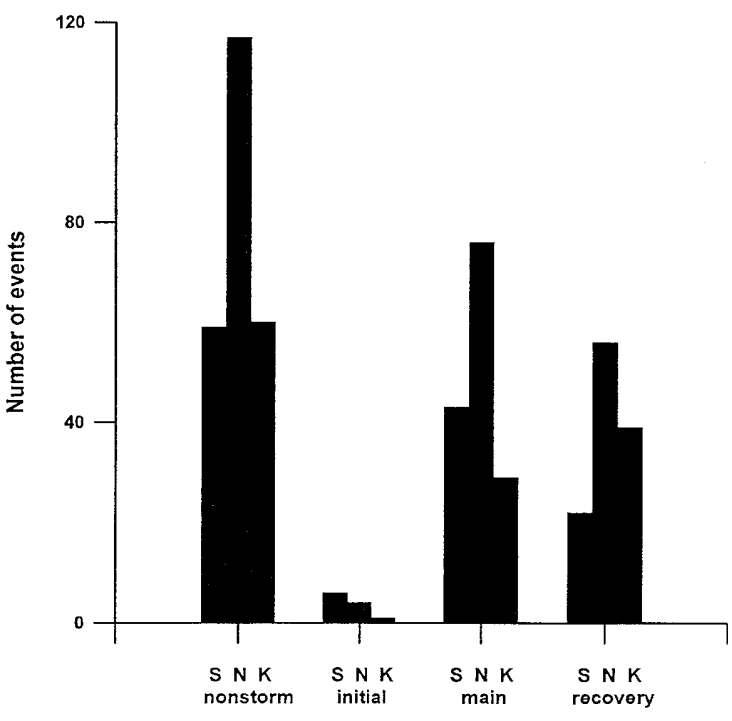

Fig. 11. Histogram of the direction of the movement of westward electrojet during different storm phases. $\mathrm{S}$ is movement to south, $\mathrm{N}$ to north and $\mathrm{K}$, the electrojet position is nearly constant. September 01, 1991 to December 31, 1996

coefficient of this relationship is 0.782 . Therefore, there is a tendency that the higher the ring current intensity, then the more equatorwards the electrojet moves. This fact agrees with Feldstein et al. (1998). However, we should also consider the considerable scatter of points for small SYM values. Nevertheless, it shows once again clearly that an equatorward movement of the westward electrojet will be accompanied by a ring current increase.

\section{Eastward electrojet}

Figures 8 and 9 show four examples of the eastward electrojet centre movement. The upper curve of the lower panel shows the temporal variation of the electrojet centre position and the lower curve shows the temporal variation of SYM-H, correspondingly. For the main phase (Fig. 8) the time variation of these two parameters conforms very well. However, during an eastward electrojet enhancement, occurring during the recovery phase or during nonstorm conditions, (Fig. 9) the electrojet also moves equatorwards. On the right panel of Fig. 13 a very close correlation between the most equatorward position of the eastward electrojet and the maximum value of SYM during the time of the positive bay is recognizable. This is in a good accordance with Feldstein et al. (1998).

\section{Discussion}

The observations of the IMAGE magnetometer chain have enabled us to investigate the relationship between the auroral electrojets occurrence and the ring current, taking into account the fact that the influence of the tail current is included in the term "ring current". We were not only interested to answer the question whether there is a causal dependence between these two phenomena 

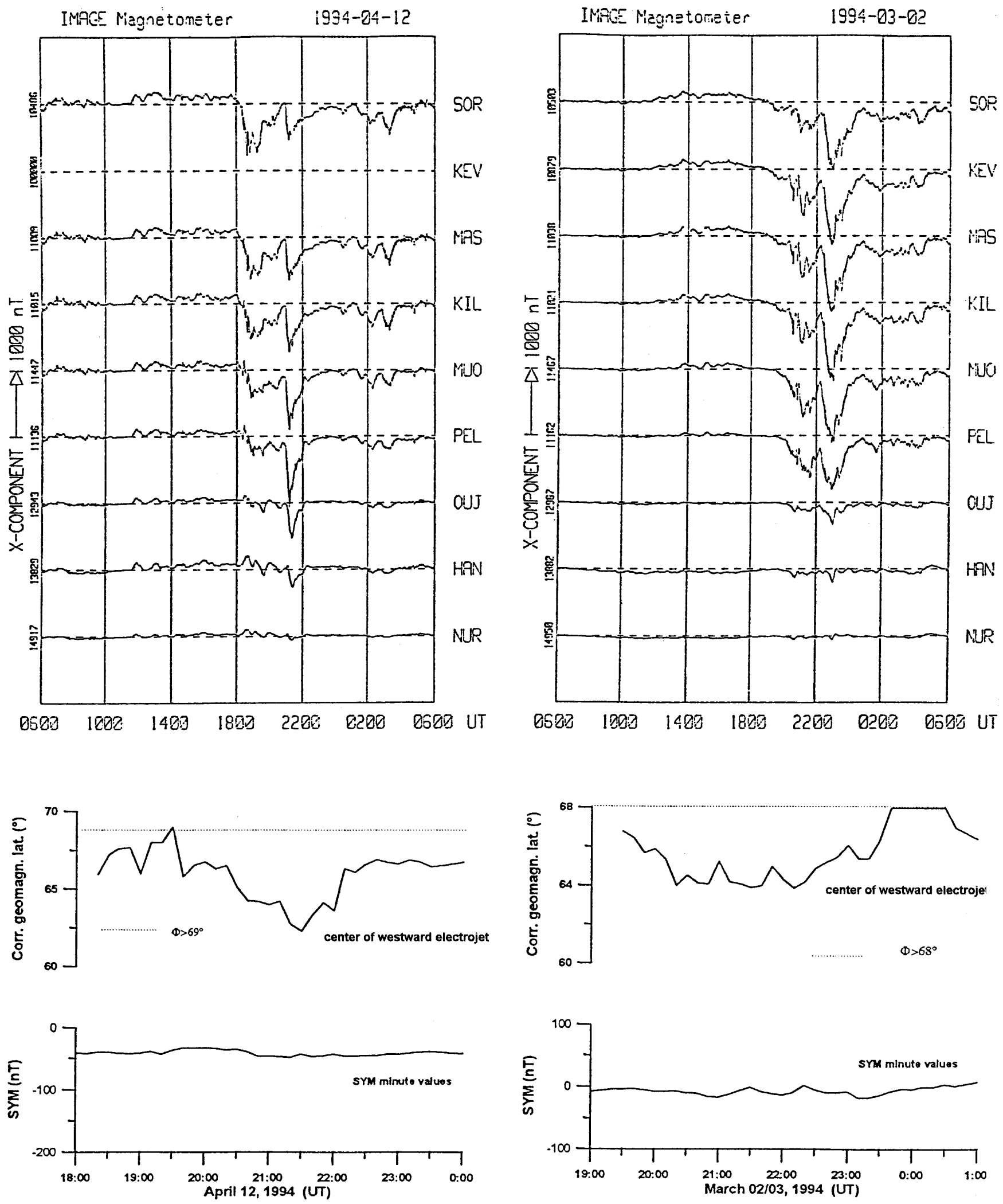

Fig. 12. Two examples of the movement of westward electrojet centre during nonstorm conditions

but also whether the electrojet movement, equatorwards as well as polewards, depends on the ring current development or vice versa. We have tried to answer these questions using statistical data and observations of single events. The deviations from the statistical mean value are always the most important. Though it is certain that both electrojets can occur at all storm phases and even during nonstorm conditions (Figs. 1,2) 


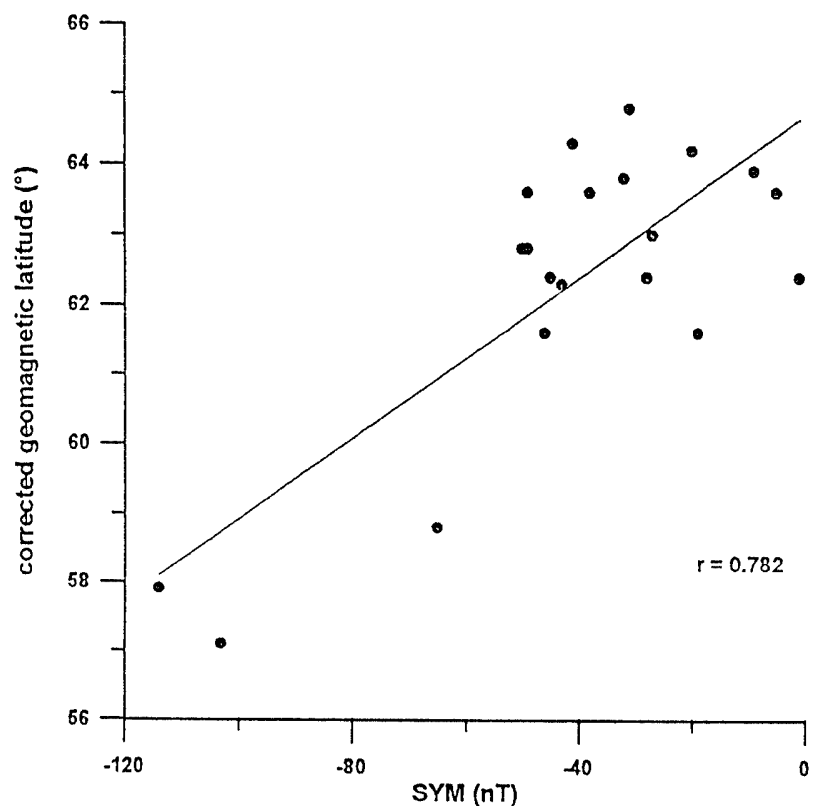

Fig. 13. Left: relationship between the most equatorward position of the westward electrojet centre and the maximum H-SYM value during the substorm including all storm phases and nonstorm conditions. Right: relationship between the most equatorward

it is evident that the eastward electrojet appears mainly during the storm main phase. For the westward electrojet this fact gives the first suggestion that it is not necessarily connected with the development of the ring current. This will be documented also by some single events shown in Figs. 4-7. It is a fact that some substorms during the recovery phase (Fig. 5) and during nonstorm conditions are not accompanied by the ring current increase, or, for the strong substorm on the left panel of Fig. 5, even by a decrease of the ring current intensity.

Though the eastward electrojet occurrence has a closer correlation to the ring current than the westward one as was shown for the main phase (see Fig. 8), such a relationship is not given for the late recovery phase and nonstorm conditions, (see Fig. 9).

However, these connections will be clearer, when presenting the electrojets movement. The most pronounced feature is the different behaviour of both electrojets. The eastward electrojet always moves equatorwards and the westward electrojet mostly polewards and often equatorwards (Figs. 10, 11). This is independent of the phase of the disturbance. During the main phase the eastward electrojet begins to move equatorwards exactly at the main phase beginning and this movement ceases at the end of the main phase. Recovery of ring current intensity and again poleward movement also develop about simultaneously (Fig. 8). Westward electrojets during the main phase can move, at the event beginning, either polewards or equatorwards (Fig. 4). This is valid also for the recovery phase (Fig. 5) and for nonstorm conditions (Fig. 12). A possible explanation of the different behaviour between the two electrojets could be the double-cause of the

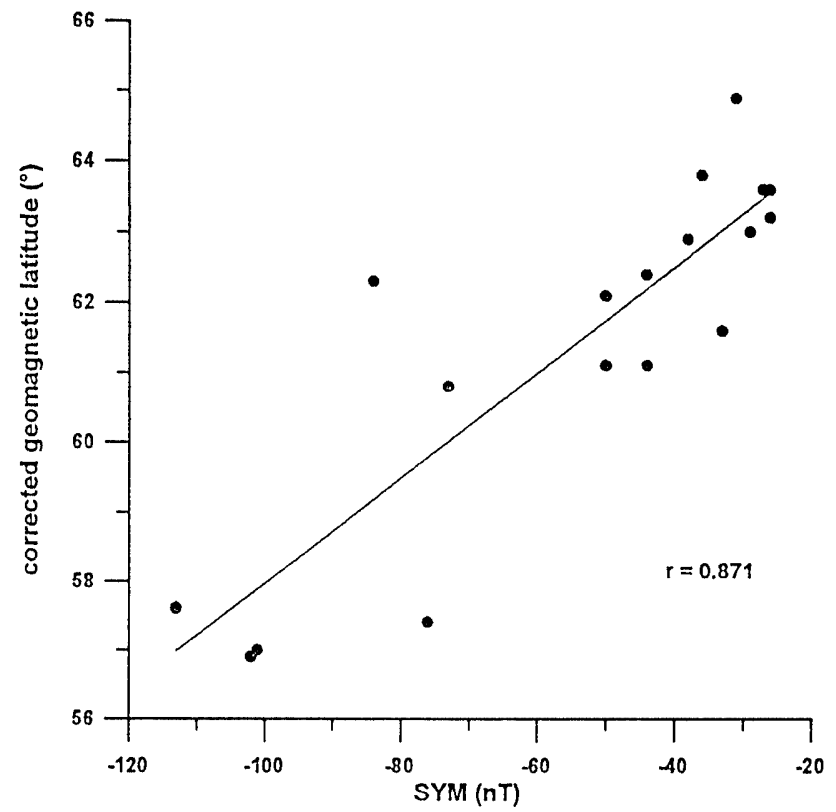

position of the eastward electrojet centre and maximum H-SYM value during the positive bay including all storm phases and nonstorm conditions

electrojets, the convection and the explosive one. In the case of the westward electrojet the convection electrojet moves equatorward and the explosive electrojet moves polewards. On the other hand both types of the eastward electrojet move equatorwards. It was shown by Grafe (1994) that also the explosive eastward electrojet moves equatorwards. Though we can also confirm the statistical results of Feldstein et al., 1998 which imply that both electrojets move further equatorwards as the ring current intensity increases (shown in Fig. 13) we should however, not forget that there are big deviations from the statistical average.

Now we return to the discussion in the introduction of this work. The results described here fit best in to the conception that the electrojets develop independently of the ring current. Our results are in a good agreement with these given by Iyemori and Rao (1996), by McPherron, 1997, and by Siscoe and Petschek (1997). Kamide et al. (1997) have partly the same opinion. But it seems that, in the inner magnetosphere, the ring current favours the conditions for the equatorward movement of the electrojets. The observations show clearly that the ring current intensity does not depend on the development of substorm intensity. This has also been shown very well by McPherron (1997). We agree with him that the substorm can not be the primary source of the ring current energy.

Acknowledgements. This work was supported by the grant INTASRFBR-95-0932. We are grateful to T. Ijemori of WDC-C2 for the minute values of H-SYM and to the IMAGE magnetometer chain team for the IMAGE data.

Topical Editor G. Chanteur thanks two referees for their help in evaluating this paper. 


\section{References}

Akasofu, S.-I., and S. Chapman, Magnetic storms: the simultaneous development of the main phase (DR) and of polar magnetic storms (DP), J. Geophys. Res., 68, 3155-3158, 1963.

Akasofu, S.-I., and S. Yoshida, Growth and decay of the ring current and the polar electrojets, J. Geophys. Res., 71, 231-240, 1966.

Alexeev, I. I., E. S. Belenkaya, V. V. Kalegaev, Y. I. Feldstein, and A. Grafe, Magnetic storms and magnetotail curents, J. Geophys. Res., 101, 7737-7747, 1996.

Balsiger, H., P. Eberhardt, J. Geiss, and D. T. Young, Magnetic storm injection of 0.9 to $16 \mathrm{keV} / \mathrm{e}$ solar and terrestrial ions into the high-altitude magnetosphere, J. Geophys. Res., 85, 1645$1662,1980$.

Balsiger, H., J. Geiss, and D. T. Young, The composition of thermal and hot ions observed by the GEOS-1 and -2 spacecraft, in energetic ion composition in the earth's magnetosphere, Johnson, 195-230, 1983.

Banks, P. M., and T. E. Holzer, The polar wind, J. Geophys. Res., 73, 6846-6854, 1968.

Burton, R. K., P. L. McPherron, and C. T. Russel, An empirical relationship between interplanetary conditions and $D_{S t}$, J. Geophys. Res., 80, 4204, 1975.

Davis, T. N., and R. Parthasarathy, The relationship between polar magnetic activity DP and growth of the geomagnetic ring current, J. Geophys. Res., 72, 5825-5836, 1967.

Eather, R. H., R. L. Carovillano, The ring current as the source region for proton auroras, Cosmic Electrodyn., 2, 105-132, 1971.

Feldstein, Y. I., and G. V. Starkov, Auroral oval in the IGY and IQSY period and a ring current in the magnetosphere, Planet. Space Sci., 16, 129-133, 1968.

Feldstein, Y. I., L. I. Gromova, V. A. Popov, and A. Grafe, Auroral electrojets dynamics during magnetic storms, Proc. Third International Conference on Substorms (ICS-3), Versailles, France, 12-17 May 1996, 75-80, 1998.

Grafe, A., Freja electron precipitation as a hint for an explosive development of the eastward electrojet, Proc. Second International Conference on Substorms, Fairbanks, Alaska, USA, 391398, 1994.

Haurwitz, M. W., Auroral substorm activity in relation to storm sudden commencement, ring current and energetic solar protons, J. Geophys., 74, 2348-2355, 1969.

Iyemori, T., Storm-time magnetospheric currents inferred from mid-latitude geomagnetic field variations, J. Geomagn. Geoelectr., 42, 1249-1265, 1990.
Iyemori, T., and D. R. K. Rao, Decay of the $D_{S t}$ field of geomagnetic disturbance after substorm onset and its implication to stormsubstorm relation, Ann. Geophysicae, 14, 608-618, 1996.

Kamide, Y., and N. Fukushima, Positive geomagnetic bays in the evening high-latitudes and their possible connection with partial ring current, Rep. Ion., Sp. Res. Japn., 26, 79-101, 1972.

Kamide, Y., R. L. McPherron, W. D. Gonzalez, D. C. Hamilton, H. S. Hudson, J. A. Joselyn, S. W. Kahler, L. R. Lyons, H. Lundstedt, and E. Szuszczecz, Magnetic storms: current understanding and outstanding questions, in Magnetic storms, Geophysical Monograph, 98, 1-17, 1998.

Liu, W. W., and G. Rostoker, Energetic ring current particles generated by recurring substorm cycles, J. Geophys. Res., 100, $21897-21910,1995$.

McPherron, R. L., The role of substorms in the generation of magnetic storms, in Magnetic Storms, Geophysical Monograph, 98, 131-147, 1997.

Pudovkin, M. I., O. J. Shumilov, and S. A. Zaitzeva, Polar storms and development of the DR currents, Planet. Space Sci., 16, 891-898, 1968.

Rostoker, G., The role of substorms in the formation of the ring current, in Workshop on the Earth's trapped environment, Ed. G. D. Reeves, p. 33, American Institute of Physics, Woodbury, NY., 1997.

Rostoker, G., W. Baumjohann, W. Gonzalez, Y. Kamide, S. Kokubun, R. L. McPherron, and B. T. Tsurutani, Comment on "Decay of the Dst field of geomagnetic disturbance after substorm onset and its implication to storm-substorm relation by Iyemori and Rao", Ann. Geophysicae, 15, 848-850, 1997a.

Rostoker, G., E. Friedrich, and M. Dobbs, Physics of magnetic storms, in Magnetic storms, Geophysical Monograph, 98, 149160, 1997b.

Shevnin, A. D., Y. I. Feldstein, and G. V. Starkov, Auroral oval and ring current in the earth's magnetosphere (in russian.), Kosmitscheskije Isledovanije, VI, 598-603, 1968.

Siscoe, G. L., and H. E. Petschek, On storm weakening during substorm expansion phase, Ann. Geophysicae, 15, 211-216, 1997.

Sun, W., W.-Y. Xu, and S.-I. Akasofu, Mathematical separation of directly driven and unloading components in the ionospheric equivalent current during substorms, J. Geophys. Res., 103, $11695-11$ 700, 1998.

Weimer, D. R., Substorm influence on the ionospheric electric potentials and currents, J. Geophys. Res., 104, 185-197, 1999.

Whalen, B. A., Low altitude energetic ion composition observations, in Energetic ion composition in the earth's magnetosphere, Johnson, 143-165, 1983. 